\title{
Riesgos y potencialidades de la era digital para la infancia y la adolescencia*
}

\author{
David Sánchez-Teruel ${ }^{1}$ \\ orcid.org/0000-0001-8996-0216 \\ María Auxiliadora Robles-Bello ${ }^{2}$ \\ (i) orcid.org/0000-0002-4317-177X \\ Universidad de Jaén, España \\ DOI: http://dx.doi.org/10.17081/eduhum.18.31.1374 \\ Recibido: 25 de febrero de 2016 \\ Aceptado: 31 de mayo de 2016

\section{Risks and potentialities in digital times for children and teenagers} \\ Palabras clave: \\ Internet, Desarrollo social, \\ Integración digital, Infancia, \\ Adolescencia.

\begin{abstract}
Resumen
La era digital ha llegado a tener tanto impacto en la sociedad actual, que la familia, la escuela, la cultura y el entorno son variables determinantes que influyen en el uso o abuso que la población infantil y adolescente hace de estas tecnologías. Este artículo muestra aquellos estudios que han centrado su interés en analizar el impacto de dispositivos digitales en las relaciones sociales de estos colectivos, ya sea a través de la familia, con los iguales o con el resto de la sociedad. Se concluye que la complejidad en las relaciones interpersonales en la infancia y adolescencia tiene un nuevo añadido: el mundo digital, que produce riesgos y potencialidades, y los consiguientes importantes retos futuros que promueve para padres, gobiernos, administraciones educativas e investigadores.
\end{abstract}

Keywords:

Internet, Social development, Digital integration,

Childhood, Adolescence.

\begin{abstract}
Digital time is making such a big impact in today's society, that families, schools, culture and environment are becoming determinant variables influenced by the use and abuse that children and teenager populations make of these technologies. This article shows those studies that have centered their interest in analyzing the impact of digital devices in the social relationships of these groups, whether being through the family, with peers or with the rest of society. It is concluded that the complexity in interpersonal relations within childhood and adolescence has an added value: the digital world that entails risks and potentialities, and consequential future challenges for parents, governments, school management, and research workers.
\end{abstract}

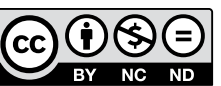

Referencia de este artículo (APA): Sánchez-Teruel, D. \& Robles-Bello, M. A. (2016). Riesgos y potencialidades de la era digital para la infancia y la adolescencia. Revista Educación y Humanismo, 18(31), 186-204. http://dx.doi.org/10.17081/eduhum.18.31.1374

\footnotetext{
* Artículo resultado en la línea de investigación Infancia y Adolescencia asociado al grupo de investigación Evaluación e Intervención Psicológica de la Universidad de Jaén, España.

1. Departamento de Psicología de la Facultad de Humanidades y Ciencias de la Educación de la Universidad de Jaén. Email: dsteruel@ujaen.es

2. Departamento de Psicología de la Facultad de Humanidades y Ciencias de la Educación de la Universidad de Jaén. Email: marobles@ujaen.es
} 


\section{Planteamiento del tema}

Hoy día nadie discute que las Tecnologías de la Información y Comunicación (TIC) suponen un elemento de especial notoriedad en numerosos ámbitos de desarrollo de la organización social, política y económica de cualquier país (Instituto Nacional de Estadística [INE], 2011a; Mannheim, 1994; Seybert, 2011; Sylwester, 2003; United Nations Educational, Scientific and Cultural Organization [UNESCO], 2005). Sin embargo, existen importantes discrepancias en cuanto a la penetración digital según zonas geográficas.

En el mundo hay 4.400 millones de personas que no poseen conexión a Internet o que la infraestructura móvil es deficitaria (Banco Interamericano de Desarrollo [BID], 2015). Pero, además, de ellas 3.400 millones viven en apenas 20 países, y un número desproporcionado vive en zonas rurales, tiene bajos recursos, presenta dificultades digitales, y por lo general suelen ser mujeres la mayoría de estas personas (BID, 2015).

En América Latina, la brecha digital se produce fundamentalmente debido a las desigualdades, de acceso y a las enormes diferencias en términos de infraestructuras (Sunkel \& Trucco, 2010). La penetración de las TIC en la región se ha ido acelerando rápidamente en los últimos años, pero así mismo ha generado brechas de acceso al equipamiento digital por clase social (Seguic, 2011). Sin embargo, investigaciones recientes plantean que, a pesar de este segmentado acceso a la tecnología, los niños y adolescentes de América Latina se están integrando al mundo digital de modo masivo. De hecho, el aumento de la conectividad en los hogares con jóvenes de edades entre 10 y 19 años es más acelerado que el que registran los hogares compuestos únicamente por mayores de 20 años (Trucco, 2014).

Según la Comisión Económica para América Latina y el Caribe (CEPAL) (2014), Internet es usado por niños y adolescentes sobre todo para obtener información y comunicarse; en concreto: desde buscar contenidos relevantes para sus estudios hasta socializarse (en diferido o en tiempo real), visitar las redes sociales, descargar música y películas y entretenerse con videojuegos en línea. En general, este colectivo accede a Internet desde el hogar (49\%) y la escuela (46\%). Sin embargo, si se analiza el acceso de una forma más pormenorizada, parecen existir importantes diferencias en los lugares de acceso según país. En Colombia, los niños y adolescentes lo usan mayoritariamente en la escuela, a diferencia de Costa Rica (56\%), México (60\%), Ecuador (64 \%), Perú (67\%) y El Salvador (81\%) donde se utiliza en el hogar. En Chile y Argentina, casi el $80 \%$ de los adolescentes con edades entre 13 y 18 años tiene teléfono móvil, porcentaje que baja al $65 \%$ en El Salvador y al $64 \%$ en México. En Brasil, las cifras de uso de redes sociales e Internet de niños desde los 9 a los 16 años superan a las de sus iguales europeos (Pavez \& Trucco, 2014). Todos estos datos confirman que el desarrollo digital en América Latina va creciendo exponencialmente ante una constante demanda social. 
En Estados Unidos, algunos estudios revelan que tan pronto los adolescentes poseen un teléfono inteligente, más del $90 \%$ lo utiliza para conectarse con redes sociales. Incluso sin poseer un dispositivo móvil muy avanzado, el $77 \%$ de los adolescentes se registra en redes sociales, y en general, casi el $50 \%$ envía mensajes de texto o WhatsApp a diario a sus amigos (Lenhart, 2012). Por otra parte, muchos niños y adolescentes estadounidenses emplean métodos multifacéticos para comunicarse con sus compañeros y amigos, incluido Internet, mensajería instantánea y sitios de redes sociales (Lenhart, Madden, Smith \& MacGill, 2007). En un informe de 2013 sobre el uso de los medios sociales y la tecnología móvil, investigadores del Pew Internet y American Life Project encontraron que el $95 \%$ de los niños y adolescentes encuestados utiliza internet, una cifra que se ha mantenido constante en los Estados Unidos desde el año 2006 (Madden, Lenhart, Duggan, Cortesi \& Gasser, 2013).

En el caso de Europa, los últimos datos ofrecidos por Eurostat, correspondientes al año 2011 (Seybert, 2011), detectan que una gran mayoría de los hogares en la Unión Europea de los 27 (UE-27) hacen uso diario de Internet, pero se acusan diferencias significativas en el acceso y utilización entre los países. Las acciones de los individuos que utilizan Internet regularmente estaban por encima de la media europea (sobre un $80 \%$ ) en seis Estados miembros: Suecia, Dinamarca, Luxemburgo, Países Bajos, Finlandia y Reino Unido. Las acciones digitales estaban por debajo del $60 \%$ en siete Estados miembros: Bulgaria, Grecia, Italia, Chipre, Polonia, Portugal y Rumanía (ver Tabla 1).

Por grupos de edad y sexo, el porcentaje de usuarios habituales de Internet (Seybert, 2011) entre las personas más jóvenes (16-24 años) fue del $91 \%$, mientras que era solo del $40 \%$ para el grupo de edad entre los 55-74 años. Básicamente, 9 de cada 10 europeos de 16-24 años utiliza Internet regularmente. No existen grandes diferencias entre hombres y mujeres que utilizan internet a diario $(70 \%$ hombres y el $65 \%$ mujeres).

En este contexto mundial, de rápido desarrollo tecnológico, aparece el concepto de ocio di-

Tabla 1. Porcentaje de europeos que usan Internet y frecuencia de uso (2011) (\% de personas)

\begin{tabular}{|l|c|c|c|c|c|}
\hline & \multicolumn{3}{|c|}{ Usuarios y No usuarios } & \multicolumn{2}{c|}{$\begin{array}{c}\text { Frecuencia de uso } \\
\text { (en promedio) }\end{array}$} \\
\hline & $\begin{array}{c}\text { Internet usado en los } \\
\text { últimos tres meses }\end{array}$ & $\begin{array}{c}\text { Internet usado en los } \\
\text { últimos 12 meses }\end{array}$ & $\begin{array}{c}\text { Nunca han } \\
\text { usado Internet }\end{array}$ & $\begin{array}{c}\text { Todos los días o } \\
\text { casi todos los días }\end{array}$ & $\begin{array}{c}\text { Por lo menos una } \\
\text { vez a la semana }\end{array}$ \\
\hline UE-27 & $71 \%$ & $73 \%$ & $24 \%$ & $56 \%$ & $68 \%$ \\
\hline Suecia*1 & $93 \%$ & $94 \%$ & $5 \%$ & $80 \%$ & $91 \%$ \\
\hline Rumanía*1 & $40 \%$ & $44 \%$ & $54 \%$ & $24 \%$ & $37 \%$ \\
\hline España & $67 \%$ & $69 \%$ & $29 \%$ & $48 \%$ & $62 \%$ \\
\hline
\end{tabular}

Fuente: Elaboración propia a partir de Seybert (2011) 
gital, que debe entenderse en el marco de la denominada Sociedad de la Información (CEPAL, 2014; European Commission-EC, 2012). Se trata de un tipo de ocio que enmarca los contenidos, no solo de Internet, sino también videojuegos, telefonía móvil y redes sociales (Quelhas, 2012). Como ya dijo Prensky (2001), en este aspecto se incluyen nuevos comportamientos y hábitos en los que niños y adolescentes (nativos digitales) se mueven con una soltura y destreza, que no deja de sorprender a los adultos (inmigrantes digitales), desconocedores de muchos de los procesos de acceso y utilización de este tipo de herramientas tecnológicas (Craft, 2012). En consecuencia, también son impresionantes los modos en que el niño y el adolescente están inmersos en este mundo digital interactivo, que los ha forjado como generación 2.0 (Defensor del Menor de la Comunidad de Madrid [DMCM], 2011; Livingstone, 2002). Así, niños y adolescentes han nacido y se han desarrollado en un contexto tecnológicamente muy avanzado, que les ha dado una intensa familiaridad con el entorno digital tanto mediático como audiovisual (García de Torres, Ruiz, Martínez \& Lavilla, 2008; Vidal, 2011).

Esa circunstancia arrastra una realidad evidente: la consideración de que los niños de hoy parecen estar más preparados que los adultos para usar sin reparo ni miedo todos los medios audiovisuales, telemáticos y digitales que les rodean (Lorenzo, 2005; Serapio, 2006). De hecho, gran parte de estudios psicosociales constatan que niños y adolescentes se han socializado interaccionando con sus iguales a través del uso de los medios digitales (Davis, 2012; Feixa, 2003; González, 2001; Gros, 2004). Ante esta realidad, algunos adultos adoptan una actitud positiva, viendo los potenciales beneficios que el uso de las tecnologías puede ofrecer a sus hijos, mientras que otros no lo consideran así (Cervera, 2009). De hecho, algunos autores plantean que su utilización trae consigo una serie de efectos negativos (ciberbullying, groooming o sexting), que van generando señales de alarma entre la opinión pública (Christakis \& Fowler, 2010; DMCM, 2011; Luengo, 2011). En esta línea, no está tan claro si este rápido desarrollo digital se complementa con una suficiente integración digital de la población adulta (inmigrantes digitales) o con una regulación legislativa (unificada por grandes territorios o por países) que promueva la protección de colectivos vulnerables, como niños y adolescentes (nativos digitales). A lo sumo, parece que gobiernos de algunos países editan guías de buen uso de las TIC o software educativo, pero no promueven acciones concretas y continuas de inclusión digital en adultos (padres, profesionales y educadores) (Bueti et al., 2009; Gregorio \& Ornelas, 2011; Insafe, 2012; Inteco, 2011a).

Algunos autores postulan que las relaciones personales a través de las TIC pierden autenticidad, densidad y quedan reducidas a contactos que solo se contabilizan (De Gracia, Vigo, Fernández \& Marcó, 2001; Fernández-Vicente, 2007; Vidal, 2011). Todo lo contrario plantean otros autores, para quienes estas herramientas ayudan a iniciar interacciones y que mantienen 
y refuerzan los lazos socioafectivos en esta población (niños y adolescentes) (Malo \& Figuer, 2010; Merino, 2011). Sin embargo, en tanto no se obtengan evidencias empíricas, se estará expuesto a un intercambio de presunciones, como las que aparecen con cierta regularidad en algunos medios de comunicación (ver p.e. RamónCortés, 2010).

Las TIC expanden las posibilidades de la comunicación, generan nuevas culturas y posibilitan el desarrollo de otras habilidades y formas de construcción del conocimiento (Iriarte, 2007; Llorente, 2008; Unesco, 2005; 2009). Puesto que la frecuencia de uso y la importancia e impacto que tienen en sus vidas es ya más que evidente, es necesario conocer y comprender en profundidad el uso que niños y adolescentes realizan de estas tecnologías: para qué y cómo las utilizan (CEPAL, 2014; INE, 2011a, 2011b; Seybert, 2011). También resulta interesante conocer cómo estas tecnologías mediatizan las relaciones interpersonales con sus padres y con otros adultos que les rodean, pero siempre desde un punto de vista objetivo, puesto que el miedo a los riesgos, que realmente sí existen (Luengo, 2011), no deberían promover actuaciones y políticas restrictivas y que atentarían contra su libertad individual (UNICEF, 2006; Vidal, 2011).

\section{Revisión y situación actual}

El uso de los soportes digitales es una constante en todas las edades (UNESCO, 2005; 2009). Sin embargo, en periodos como la niñez o adolescencia es donde se aprecia un mayor in- cremento (Berríos \& Buxarrais, 2005). Estudios anteriores plantearon que los medios digitales se podían analizar y clasificar, basándose en el uso dado por niños y adolescentes, según los siguientes tipos: 1) lúdico y de ocio, 2) comunicación e información y 3) educativo (Albero, 2002; Gil, Feliú, Rivero \& Gil, 2003; Gros, 2004; Naval, Sádaba, Bringué \& Pérez, 2003). Así, niños y adolescentes dicen utilizar el ordenador e Internet principalmente para jugar y hablar con sus amigos y amigas, bajar música y películas. También consideran la red un importante medio de comunicación (uso de chat a través de Skype o Messenger son actividades regulares que se practican a diario) y, además, informan del uso de móviles inteligentes (WhatsApp, videos, etc.) para jugar, enviar mensajes o comunicarse con iguales o con adultos (padres, familiares, etc.). Asimismo de los estudios mencionados se desprende que se puede unir la actividad del videojuego con el aprendizaje (Albero, 2002; Balaguer, 2002; Gil et al., 2003; Gros, 2004; Naval et al., 2003). Mediante los videojuegos los niños y adolescentes construyen conocimientos útiles, con los cuales consiguen una solvencia informática que también les permite realizar sus apuntes, escribir trabajos y buscar información sobre sus asignaturas.

En edades tempranas (de 3 a 8 años), algunos padres y educadores ven con cierta desconfianza que los niños se enamoren del ordenador o portátil, ya que consideran que fomenta el aislamiento y deteriora el desarrollo de las habilidades sociales (De Gracia et al., 2001). De hecho, para mu- 
chos padres, los mayores problemas llegan con la conexión a Internet, una extraordinaria herramienta de información y comunicación que, sin embargo, puede contener riesgos si los menores la utilizan sin supervisión (Gutiérrez, 2004). En primera instancia, parece que es un compromiso o desafío de padres y profesionales garantizar que las primeras experiencias con la tecnología sean las más adecuadas para el desarrollo y formación de los niños, pero la realidad no es tan evidente, como lo demuestra el hecho de que no todos parecen estar de acuerdo sobre lo positivo o negativo del uso de esta tecnología (Cervera, 2009; Vidal, 2011).

Con base en la dinámica que tienen hoy los recursos tecnológicos en el interior de los hogares, se apoya la hipótesis de que la familia juega un papel muy importante en la generación de una determinada cultura frente a la era digital, pero después la propia familia no sabe cómo regularla (Iriarte, 2007). En este sentido, debe considerarse que el acceso a soportes digitales por parte de madres y padres aún es limitado, ya que como ambos tienen escasa familiaridad con este asunto, generalmente delegan la responsabilidad de enseñar a niños y adolescentes (formación, uso y aprovechamiento) a los centros educativos. De hecho, aspectos socioeconómicos, como los nuevos tipos de familias, en donde ambos progenitores trabajan, o la falta de tiempo del/la tutor/a del niño $u$ otras situaciones psicoeducativas, pueden producir una estructuración familiar diversificada que en mayor o menor medida afecta el acceso sin supervisión sobre las herramientas digitales de esta población hasta llegar al abuso. En semejante situación, parece ser que la familia se convierte en ese momento en un escenario de confrontación de dos generaciones muy distantes: una es tecnológicamente inmigrante, la de los padres, y otra es la digitalmente ilustrada casi desde el nacimiento, la de los hijos (Malo \& Figuer, 2010). En este caso, los hijos tendrán siempre las de ganar, a menos que los padres se formen en la era digital. Solo así, el diálogo de sordos cotidiano se puede traducir en una interlocución productiva que permita crear un criterio adecuado de uso para niños y adolescentes frente a las oportunidades y riesgos que las TIC pueden arrastrar (Díaz \& Vicente, 2011).

En esta línea, algunos autores plantean la existencia de consecuencias psicosociales negativas del abuso de los medios digitales (Balaguer, 2002), como pueden ser la adicción (Echeburúa, Labrador \& Becoña, 2009), el ciberacoso (entre iguales o entre un adulto y un niño) o el aislamiento social (García de Torres et al., 2008; Ramón-Cortés, 2010). Así, padres, educadores $\mathrm{y}$ expertos coinciden en que los dos principales problemas con los que se encuentran los niños en Internet son los contenidos inapropiados y el contacto con extraños (Becerra \& García-León, 2012; Echeburúa et al., 2009; Tejerina, 2010). El primero de ellos ocurre de forma sencilla y a menudo casual, como cuando se encuentran con una palabra confusa en un motor de búsqueda. El segundo tiene como escenario habitual el anonimato de los chats o redes sociales. Todas estas herramientas (motores de búsqueda, redes 
sociales, etc.) son frecuentemente utilizadas por los menores y, desgraciadamente, en los últimos años ha aumentado el número de niños que han realizado o sufrido ciberbullying (Livingstone \& Palmer, 2012; Luengo, 2011), luego de acudir a una cita con un desconocido (DMCM, 2011; Observatorio de las Telecomunicaciones y de la Sociedad de la Información [OTSI], 2005), o han realizado o sufrido otros actos delictivos (suplantación de identidad, vulneración de propiedad intelectual, acoso sexual o grooming, imágenes o videos en posturas provocativas o sexting, fraudes, riesgos económicos o maleware, etc.) auspiciados, todos ellos, por el anonimato de la red (Instituto Nacional de Tecnologías de la Comunicación [Inteco], 2009). Además, algunos de estos comportamientos (p.e.: adicción, imágenes o videos en posturas provocativas o sexting pasivo o activo, acceso a contenidos inapropiados para la edad, amenazas a la privacidad, etc.) se han disparado en los últimos años entre niños y adolescentes, con la aparición de los móviles inteligentes o Smartphones (Flores, 2011; Inteco, 2011a; 2011b).

Sin duda, los riesgos que acarrean las TIC y teléfonos móviles existen, y son muy preocupantes, pero de ninguna manera se puede culpar al medio; sería como prohibir conducir porque existen muchos accidentes de tráfico. Es claro que sobre estos entornos se propagan luces y sombras (Area, Gros \& Marzal, 2008; Merino, 2011). No obstante, varios estudios anteriores ya matizaron esta realidad tan preocupante (Amorós, Buxarrais \& Casas, 2002; Gil et al., 2003): los niños y adolescentes no utilizan las tecnologías para aislarse, sino que las usan como una herramienta fundamental para relacionarse. Buen número de administraciones (DMCM, 2011; EC, 2012; Unesco, 2009) y especialistas (Area, 2009; Davis, 2012; Craft, 2012) han planteado que los niños aprenden construyendo su propio conocimiento y descubriendo continuamente cosas nuevas. Con base en esta premisa, parece correcto facilitar el uso de las tecnologías, porque retaría al niño a que desarrolle su propio proceso de aprendizaje, eso sí, siempre siendo conscientes de los riesgos y no delegando tal responsabilidad en otras instituciones o profesionales. Algunos estudios plantean que los padres demuestran ser conscientes de la incidencia de los riesgos que amenazan a sus hijos, aunque se observa en general un conocimiento inferior al manifestado por sus hijos (INTECO, 2011a). Además, los menores reconocen más fácilmente las situaciones problemáticas ajenas que las propias, y de este modo, declaran que las situaciones constitutivas de riesgo tienen lugar en mayor medida en su entorno que las ocurridas a ellos mismos (Inteco, 2011a). Todos estos aspectos vienen a resaltar lo que ya otros autores plantearon en el pasado (Ruiz \& Gallardo, 2002): es importante que el adulto se implique en el aprendizaje y la convivencia de los soportes digitales en familia, educando a los menores en la responsabilidad y no en la restricción, para favorecer un clima de confianza en el hogar que permita a los menores acudir a sus padres o adultos de referencia, en caso de producirse alguna incidencia. Pero para ello es fundamental que el hogar se convierta en un espacio digital democratizado. 
Por tanto, la labor de padres y madres pasa primero por reforzar sus conocimientos sobre dispositivos digitales al mismo tiempo que deben disponerse a crear un clima de confianza con sus hijos, en donde la seguridad sea una tarea en equipo (Flores, 2010; Inteco, 2009). Los adultos deberían estar preparados para escuchar, apoyar y ayudar a sus hijos en caso de que se produzca algún incidente. Lo recomendable es conocer las circunstancias y usos en los que ocurren todos estos riesgos para el menor, así como progresar en el estudio de sus orígenes, para entonces sí poder aplicar las medidas de prevención pertinentes (Inteco, 2011a; Sádaba, 2010). De hecho, en la propia red existe una gran cantidad de información técnica y científica, avalada por expertos, destinada a ayudar a los padres, profesionales y a los propios menores en la lucha contra los riesgos de las TIC y móviles inteligentes, desde un punto de vista objetivo, para no perder de vista las potencialidades que estas herramientas ofrecen (Asociación de Internautas, 2012; Insafe, 2012; Inteco, 2011a, 2011b; Pantallas Amigas, 2012; Protégeles, 2012; Tejerina, 2012) (Ver Anexo).

Por otro lado, metanálisis recientes han llegado a conclusiones de interés para padres y profesionales, que pueden servir para disipar algunas dudas y aclarar perspectivas (Spies \& Margolin, 2014). En general, parece ser que Internet y las redes sociales no son el origen de que los niños y adolescentes tengan mayores habilidades sociales y por tanto mayor número de amigos, sino que aquellos que tienen mejores competencias sociales of-line (vida real), también se muestran más activos on-line (vida digital). Sin embargo, es importante plantear que en aquellos casos donde existen dificultades de integración social of-line (por factores psicosociales, enfermedades crónicas, dificultades geográficas, por pertenecer a diversidades étnicas, raciales o sexuales, etc.), la reciprocidad social positiva en Internet y redes sociales podría convertirse en moduladora de una mayor integración social, lo que les llevaría a emitir conductas prosociales of-line e incrementar su identidad colectiva (Markstrom, 2010; McKenna, Green \& Gleason, 2002; Silenzio et al., 2009; Yu, Taverner \& Madden, 2011). Todos estos aspectos son claves fundamentales que pueden promover niveles mayores de resiliencia ante dificultades reales tal y como lo han planteado revisiones anteriores (Sánchez-Teruel \& Robles-Bello, 2014).

También parece ser que niños y adolescentes no utilizan Internet habitualmente para buscar nuevas amistades, sino más bien estas herramientas se convierten en extensiones sobre actividades y comentarios de sus relaciones of-line (Reich, Subrahmanyam \& Espinoza, 2012). De hecho, el contenido de la mayoría de la comunicación digital, ya sea por ordenador o móvil, se centra en los acontecimientos cotidianos relacionados con la escuela y con las actividades futuras a realizar con amigos mutuos y habituales. En esta línea, los soportes digitales se convierten en instrumentos fundamentales de autorrevelación, que pueden servir a padres, educadores, iguales y profesionales, para reconocer las primeras so- 
licitudes de ayuda en niños y adolescentes, lo que podría facilitar la identificación temprana de riesgos psicopatológicos o psicosociales graves (Caprara, Gerbino, Paciello, Di Giunta \& Pastorelli, 2010; Spies \& Margolin, 2014).

\section{Conclusiones}

Este artículo centra la atención en los cambios que las tecnologías de la información y la comunicación producen en la infancia y adolescencia. Como se ha mostrado, existen luces y sombras, es decir, ventajas o aspectos positivos que las tecnologías aportan a la vida de quienes las usan, e inconvenientes o riesgos que pueden surgir de su uso, sobre todo cuando este no es supervisado por un adulto competente y bien formado. Se entiende este adulto como aquel que debe manejar la tecnología de forma diaria, y además aprender aquellos aspectos digitales que le resulten desconocidos. Partiendo de esta realidad, es evidente que cada día y casi sin darnos cuenta, lo digital invade nuestra cotidianidad. De hecho, se contempla como una tarea conjunta, entre administraciones competentes, padres, profesionales, expertos y los propios menores, el conseguir que este colectivo, tan asiduo y a la vez tan vulnerable, conozca los riesgos y las potencialidades del mundo digital que le rodea sin que ello suponga una merma en sus libertades y usos tal y como han propuesto algunas administraciones internacionales (Unicef, 2006). Así pues, uno de los retos más importantes para legisladores, padres, profesionales e investigadores, debe sin lugar a dudas centrarse en el estudio de la relación que niños y adolescentes establecen con iguales o con adultos utilizando estas herramientas como medio de interacción, de ocio y de aprendizaje.

Este artículo plantea diversas perspectivas futuras para investigadores y profesionales interesados en estos aspectos. El realizar estudios comparativos sobre currículos escolares de escuelas e institutos donde se incluya el manejo de las tecnologías para comprobar la minimización de riesgos podría ser una línea de investigación futura. Pero, además, deberían incluirse en los currículos universitarios de profesionales de la Educación, Pedagogía y Psicología contenidos y asignaturas sobre el impacto psicosocial de dispositivos digitales y medios de comunicación social (social media), para fomentar el estudio de sus grandes potencialidades y minimizar sus riesgos en la educación e intervención psicosocial. También podría ser de interés para futuros investigadores el estudio comparativo y transcultural del impacto de las tecnologías según países y zonas geográficas del mundo, puesto que los riesgos como el ciberbullying, grooming o el sexting se producen en todos los países, aunque el nivel de penetración digital sea diferenciado.

\section{Referencias}

Albero, M. (2002). Adolescentes e Internet: Mitos y realidades de la sociedad de la información. Revista de estudios de comunicación, 3, 55-62.

Amorós, P., Buxarrais, M. R. \& Casas, F. (2002). La influencia de les tecnologies de la informació i comunicació en la vida dels nois de 12 a 16 anys. Barcelona: Institut d'Infáncia Mon Urbá. Observatorio de la Infancia y la Familia. 
Area, M. (2009). Introducción a la tecnología educativa. Tenerife: Universidad de La Laguna.

Area, M., Gros, B. \& Marzal, M. A. (2008). Alfabetizaciones y TIC. Madrid: Síntesis.

Asociación de Internautas (2012). Web de ayuda. Recuperado desde http://www.internautas.org/

Balaguer, R. (2002). Videojuegos, Internet, infancia y adolescencia del nuevo milenio. Recuperado desde http://www.fices.unsl. edu.ar/kairos

Banco Interamericano de Desarrollo (BID) (abril, 2015). Innovación y tecnologías de la información: Reimaginando el futuro de las Américas. Trabajo presentado en la II Cumbre Empresarial de las Américas, Panamá.

Becerra, J. A. \& García-León, A. (2012). Características psicosociales de delincuentes sexuales infantiles y distribuidores de pornografía infantil en Internet. En J. A. Muela-Martínez, A. García-León \& A. Gómez (Eds.), Perspectivas en psicología aplicada (pp.31-46). Jaén: Centro Asociado a la UNED Andrés de Vandelvira.

Berríos, L1. \& Buxarrais, M. R. (2005). Las tecnologías de la información y la comunicación (TIC) y los adolescentes. Recuperado desde la Organización de Estados Iberoamericanos. Disponible en: http:// www.oei.es/historico/valores2/monografias/monografia05/reflexion05.htm
Bueti, C., Cantarino de Frías, M. J., Carr, J., Carstensen, D., De Paoli, C., Laiho, M. \& Richardson, J. (2009). Protección de la infancia en línea: Directrices para los niños. Ginebra (Suiza): Unión Internacional de Telecomunicaciones.

Caprara, G. V., Gerbino, M., Paciello, M., Di Giunta, L. \& Pastorelli, C. (2010). Counteracting depression and delinquency in late adolescence. The role of regulatory emotional and interpersonal self efficay beliefs. European Psychologist, $15,34-48$.

Cervera, L. (2009). Lo que hacen tus hijos en Internet. Barcelona: Integral.

Christakis, N. \& Fowler, J. (2010). Conectados. El sorprendente poder de las redes sociales y cómo nos afectan. Madrid: Taurus.

Comisión Económica para América Latina y el Caribe (CEPAL) (2014). El uso seguro de las TIC puede ayudar a niños y adolescentes a ejercer mejor sus derechos. Recuperado desde http:/www.cepal.org/es/ comunicados/uso-seguro-de-las-tic-puede-ayudar-ninos-y-adolescentes-ejercermejor-sus-derechos

Craft, A. (2012). Childhood in a digital age: creative challenges for educational futures. London Review of Education, 10, 173-190. DOI: 10.1080/14748460.2012.691282.

Davis, K. (2012). Friendship 2.0: Adolescents' experiences of belonging and self-disclosure online. Journal of Adolescence. In Press. 
Defensor del Menor de la Comunidad de Madrid (DMCM) (2011). Informe anual $2011 \mathrm{del}$ defensor del menor de la comunidad de Madrid. Madrid: Autor.

De Gracia, M., Vigo, M., Fernández, M. J. \& Marcó, M. (2001). Problemas conductuales relacionados con el uso de Internet: Un estudio exploratorio. Anales de Psicología, 18, 273-292.

Díaz, M. T. \& Vicente, A. (2011). Los jóvenes como consumidores en la era digital. Revista Electrónica Interuniversitaria de Formación del Profesorado, 14, 127-134.

Echeburúa, E., Labrador, F. J. \& Becoña, E. (2009). Adicción a las nuevas tecnologías en adolescentes y jóvenes. Madrid: Pirámide.

European Commission (EC) (2012). The Information and Communication Technologies Policy Support Programme (ICT-PSP). Luxembourg: European Commission.

Feixa, C. (2003). Generación@. La adolescencia en la era digital. Cuadernos de Pedagogía, 320, 52-55.

Fernández-Vicente, A. (2007). Crítica de la tecnología del reencantamiento: La comunicación en la era digital. Tesis doctoral no publicada, Universidad de Murcia, España.

Flores, J. (2009). Nuevos modelos de comunicación, perfiles y tendencias en las redes sociales. Comunicar, 33, 73-81. DOI: 10.3916/c33-2009-02-007.

Flores, J. (noviembre, 2010). Uso seguro de las redes sociales: Pautas preventivas y fomento de la ciudadanía digital respon- sable. Trabajo presentado en VI Jornadas Infancia y Adolescencia TIC: Oportunidades y retos de las redes sociales, Vizcaya, España.

Flores, J. (2011). Sexting, una práctica de riesgo. Recuperado desde http://www.pantallasamigas.net/proteccion-infancia-consejosarticulos/sexting-una-practica-de-riesgo. shtm

García de Torres, E., Ruiz, S., Martínez, S. \& Lavilla, M. J. (2008). El uso de los nuevos medios por la audiencia infantil y juvenil: tendencias en la investigación. En F. Sabés \& J. J. Verón (Eds.), Internet como sinónimo de convergencia mediática y tecnológica (pp.61-73). Zaragoza: Asociación de la Prensa de Aragón.

Gil, A., Feliú, J., Rivero, I. \& Gil, E. (2003). ¿Nuevas tecnologías de la información y la comunicación o nuevas tecnologías de relación? Niños, jóvenes y cultura digital. [Artículo en línea]. UOC. Recuperado desde http://www.uoc.edu/dt/20347/ index.html

González, J. N. (2001). Hacia una reforma educativa en la era digital. Revista Iberoamericana de Educación, 26, 77-96.

Gregorio, C. G. \& Ornelas, L. (2011) (Comp.). Protección de datos personales en las redes sociales digitales: en particular de niños y adolescentes (Memorándum de Montevideo). México D.F.: Instituto Federal de Acceso a la Información y Protección de Datos. 
Gros, B. (Coord.) (2004). Pantallas, juegos y educación. La alfabetización digital en la escuela. Bilbao: Desclée de Brouwer.

Gutiérrez, A. (2004). Alfabetización digital. Más allá de teclas y ratones. Barcelona: Gedisa.

INSAFE (2012). Red europea de nodos nacionales de sensibilización sobre un uso seguro de Internet y resto de TIC. Recuperado desde http://www.centrointernetsegura. es/insafe.php

Instituto Nacional de Estadística (INE) (2011a). Encuesta sobre equipamiento y uso de TIC en los hogares durante el año 2011. Madrid: Autor.

Instituto Nacional de Estadística (INE) (2011b). Uso de TIC por edades ambos sexos en España correspondiente a los datos del 2011. Recuperado desde http://www.ine. es/jaxi/tabla.do

Instituto Nacional de Tecnologías de la Comunicación (INTECO) (2009). Estudio sobre hábitos seguros en el uso de las TIC por niños y adolescentes y e-confianza de sus padres. Madrid: Observatorio de la Seguridad de la Información del Ministerio de Industria, Energía y Turismo.

Instituto Nacional de Tecnologías de la Comunicación (INTECO) (2011a). Estudio sobre hábitos seguros en el uso de Smartphones por los niños y adolescentes españoles. Madrid: France Telecom España (Orange) y Observatorio de la Seguridad de la Información del Ministerio de Industria, Energía y Turismo.
Instituto Nacional de Tecnologías de la Comunicación (Inteco) (2011b). Guía sobre adolescencia y sexting: qué es y cómo prevenirlo. Madrid: Pantallas Amigas y Observatorio de la Seguridad de la Información del Ministerio de Industria, Energía y Turismo.

Iriarte, F. (2007). Los niños y las familias frente a las tecnologías de la información y las comunicaciones (TIC). Psicología desde el Caribe, 20, 208-224.

Lenhart, A. (2012). Teens, Smartphones \& Texting. Recuperado desde http://www. pewinternet.org/Reports/2012/Teens-andsmartphones/Summary-of-findings.aspx

Lenhart, A., Madden, M., Smith, A. \& Macgill, A. (2007). Teens and social media, report: Teens, Social Networking, Blogs, Videos, Mobile. Recuperado desde http://www. pewinternet.org/Reports/2007/Teens-andSocial-Media.aspx

Livingstone, S. (2002). Young people and new media. London: Sage.

Livingstone, S. \& Palmer, T. (2012). Identifying vulnerable children online and what strategies can help them. London: U.K. Safer Internet Centre.

Llorente, M. C. (2008). Blended learning para el aprendizaje en nuevas tecnologías aplicadas a la educación: un estudio de caso. Tesis doctoral no publicada, Universidad de Sevilla, España.

Lorenzo, J. (2005). La lectura en la Generación Red. Jóvenes, lectura e Internet. Revista de Estudios de Juventud, 70, 65-79. 
Luengo, J. A. (2011). Ciberbullying: Guía de recursos para centros educativos en caso de ciberacoso. Madrid: Defensor del Menor de la Comunidad de Madrid.

Madden, M., Lenhart, A., Duggan, M., Cortesi, S. \& Gasser, U. (2013). Teens and technology. Recuperado desde http://www. pewinternet.org/Reports/2013/Teens-andTech.aspx

Malo, S. \& Figuer, C. (2010). Infancia, adolescencia y tecnologías de la información y la comunicación (TIC) en perspectiva psicosocial. Intervención Psicosocial, 19, 5-8.

Mannheim, K. (1994). Diagnóstico de nuestro tiempo. México D.F.: Fondo de Cultura Económica.

Markstrom, C. A. (2010). Identity formation of American Indian adolescents: local, national, and global considerations. Journal of Research on Adolescence, 21(2), 519-535. DOI: 10.1111/j.1532-7795.2010.00690.x McKenna, K. Y. A., Green, A. S. \& Gleason, M. E. J. (2002). Relationship formation on the Internet: What's the big attaction? Journal of Social Issues, 58, 9-32.

Merino, L. (2011). La cotidianeidad tecnológica de la generación digital. Revista Vasca de Sociología y Ciencia Política, 50, 97-108. Naval, C., Sádaba, C., Bringué, X. \& Pérez, P. (2003). Los lenguajes de las pantallas. Impacto de las relaciones sociales de los jóvenes y retos educativos. Barcelona: Universitat de Barcelona.
Observatorio de las Telecomunicaciones y de la Sociedad de la Información (OTSI). (2005). Infancia y adolescencia en la sociedad de la información. Análisis de la relación con las TIC en el hogar. Red.es. UOC. Recuperado desde http://observatorio.red.es/estudios/documentos/infancia_tecnologia.pdf

Pantallas Amigas (2012). Web de información para padres y menores. Recuperado desde http://www.pantallasamigas.net/

Pavez, M. I. \& Trucco, D. (2014). Niños, niñas y adolescentes de América Latina y el Caribe en el mundo digital. Revista Desafios, $18,4$.

Prensky, M. (2001). Digital Natives, Digital Immigrants. On the Horizon, 9, 1-6.

Protégeles (2012). Dossier informativo. Recuperado desde http://www.centrointernetsegura.es/descargas/dossier_protegeles_2012.pdf

Quelhas, P. (2012). Tweens' characterization of digital technologies. Computers \& Education, 59, 580-593.

Ramón-Cortés, F. (2010). ¿Internet amenaza el contacto real? El País. Recuperado desde http://elpais.com/diario/2010/01/03/ eps/1262503611_850215.html

Reich, S., Subrahmanyam, K. \& Espinoza, G. (2012). Friending, IMing, and hanging out face-toface: Overlap in adolescents online and offline social networks. Developmental Psychology, 2, 356-368. DOI: 10.1037/a0026980. 
Ruiz, I. \& Gallardo, J. A. (2002). Impacto psicológico de la negligencia familiar (leve versus grave) en un grupo de niños y niñas. Anales de Psicología, 18, 261-272.

Sádaba, Ch. (2010). El perfil del usuario de Internet en España. Intervención Psicosocial, 19, 41-55.

Sánchez-Teruel, D. \& Robles-Bello, M. A. (2014). Personalidad y resiliencia en un cuerpo especial de la Policía Nacional de España. Journal of Work and Organizational Psychology, 30, 75-81. DOI: 10.1016/j.rpto.2014.06.003.

Seguic, J. (2011). El crecimiento de redes sociales en América Latina. La influencia de los medios sociales en el escenario digital de América Latina. Recuperado desde: http:/interactivo.cl/descargas/Latin_America_Social_Networking_Study_2011_Final_Spanish.pdf

Serapio, A. (2006). Realidad psicosocial: la adolescencia actual y su temprano comienzo. Revista de Estudios de Juventud, 73, 11-23.

Seybert, H. (2011). Internet use in households and by individuals in 2011. Luxembourg: Eurostat.

Silenzio, V. M., Duberstein, P. R., Tang, W., Lu, N., Tu, X. \& Homan, C. M. (2009). Connecting the invisible dots: reaching lesbian, gay, and bisexual adolescents and young adults at risk for suicide through online social networks. Social Science \& Medicine, 69(3), 469-474. DOI: 10.1016/j. socscimed.2009.05.029.
Spies, L. A. \& Margolin, G. (2014). Growing up wired: Social Networking Sites and adolescent psychosocial development. Clinical Child and Family Psychology Review, 17(1), 1-18. DOI: 10.1007/s10567-0130135-1.

Sunkel, G. \& Trucco, D. (2010). TIC para la educación en América Latina. Riesgos y oportunidades. Serie Políticas Sociales, $167,1-7$.

Sylwester, R. (2003). A biological brain in a cultural classroom: Enhancing cognitive and social development through collaborative classroom management. Thousand Oaks, CA: Corwin Press.

Tejerina, O. (2010). Infracciones frecuentes en la Red: comportamientos castigados por la ley. Recuperado desde http://tejerina. es/2010/05/21/infracciones-frecuentesen-la-red-comportamientos-castigadospor-la-ley/

Tejerina, O. (2012). Derechos humanos y nuevas tecnologías. Recuperado desde http:// tejerina.es/

Trucco, D. (2014). Educación y desigualdad en América Latina. Santiago (Chile): Naciones Unidas.

UNICEF (2006). Convención sobre los derechos del niño. Recuperado desde http:// www.unicef.es/sites/www.unicef.es/files/ CDN_06.pdf

United Nations Educational, Scientific and Cultural Organization (UNESCO) (2005). Hacia las sociedades del conocimiento. París: Author. 
United Nations Educational, Scientific and Cultural Organization (UNESCO) (2009). Tecnologías de la información y las comunicaciones para el desarrollo sostenible (Consejo Ejecutivo 181 EX/55). París: Author.

Vidal, M. S. (2011). Victimización del menor ante las nuevas tecnologías de la información y comunicación. Tesis de maestría, Universidad Complutense de Madrid, España.

Yu, J., Taverner, N. \& Madden, K. (2011). Young people's views on sharing health-related stories on the Internet. Health and Social Care in the Community, 19(3), 326-334.

\section{ANEXO}

Guía básica para adultos y menores sobre el uso adecuado de las herramientas digitales en el entorno familiar

Las pautas que se plantean a continuación tienen como objetivo implicar a los adultos (padres) en la vida digital de sus hijos, para que sea lo más sana posible y así evitar la prohibición reactiva ante posibles situaciones de riesgo. Por ello todas las pautas que a padres, menores y adolescentes aquí se muestran, están basadas en resultados de investigaciones de diversas administraciones (Inteco, 2011a, 2011b; Insafe, 2012) y expertos (Flores, 2009; 2010; 2011; Livingstone \& Palmer, 2012; Tejerina, 2012) sobre el mal uso, en este colectivo, de los soportes tecnológicos:

\section{Pautas y normas de uso de móviles}

- Los tiempos de uso y servicios del móvil (funciones de música, juegos, cámara, acceso a Internet, aplicaciones, etc.) deben ser razonables y estar previamente pactados.

- Los espacios o lugares para la utilización de estos dispositivos en momentos de ocio deben ser espacios comunes de colegios o del hogar o frente a habitaciones.

- El límite mensual de gasto debe estar establecido. Para ello, los adultos pueden informarse y conocer las tarifas de uso y los mecanismos y procesos de descargas, créditos virtuales, recargos al sobrepasar la tarifa de datos, etc.

\section{2. ¿Cómo actuar ante situaciones de ries-} go?: Consejos para padres

Uso excesivo: Hablar con el menor sobre el tiempo que pasa conectado (Internet o Smartpho$n e)$ y establecer un límite diario o semanal.

Adicción: Estar atento al comportamiento del menor y si presenta síntomas de cansancio o conductas dependientes (nerviosismo, irritabilidad, aislamiento) cuando no se conecta o no tiene su móvil, actuar para que el menor descanse o realice otro tipo de actividades.

Acceso a contenidos inadecuados: Interesarse por los contenidos preferidos de los menores y aquellos que les hacen sentir incómodos. Consensuar con ellos los contenidos a los que puede o no acceder, tratando de que el menor sea consciente de lo nocivo que le puede resultar, de tal manera que se sienta responsable de su propio bienestar.

Amenazas a la privacidad: Evitar en la medida de lo posible que el menor almacene datos sensibles en el ordenador o móvil, en especial, 
imágenes y vídeos que ayuden a otros a identificar a quienes aparecen en ellos. Además, hacer hincapié en los riesgos de compartir información, bien sea propia (del menor), o bien, de otros menores, con amigos o con terceros. El mensaje principal que se debe trasladar a los menores es: Cuando envías una información a través de Internet, redes sociales o móviles pierdes el control sobre ella y su destino; piensa antes de publicar. Por tanto, es conveniente revisar junto con los hijos las solicitudes de permisos que aparecen al realizar una descarga, valorando qué permisos se conceden (acceso a la tarjeta de memoria, conexión a Internet, intercambio de datos, etc.). Respecto a la pérdida o sustracción del Smartphone (si no está protegido), incidente que se produce con relativa frecuencia, permite revelar a terceros datos sensibles sobre el menor. Para evitarlo, los padres pueden utilizar aplicaciones que ayuden a localizar el terminal de sus hijos y luego cifrar los datos sensibles, o borrar de forma remota la información que contiene, con lo que se impide el acceso no autorizado de terceros.

Ciberbullying: Concienciar a los hijos sobre las repercusiones de los comportamientos asociados a esta práctica, tanto activa como pasiva, y vigilar los posibles cambios en el comportamiento del menor que puedan ser un indicativo de una situación de acoso (enfado, irritabilidad, desánimo, etc.). Como los padres son el referente más cercano, es importante darles la confianza suficiente para que recurran a ellos ante cualquier incidente que les haga sentir mal.

Grooming: Hacer hincapié sobre los riesgos de contactar con desconocidos a través de Internet, cámaras web, teléfonos inteligentes, tabletas, etc... Explicarles la importancia de añadir solo a amigos en los servicios y aplicaciones de mensajería y redes sociales. En caso de establecer un encuentro físico o personal, acudir siempre acompañado de un adulto.

Sexting: Explicarles las repercusiones del envío de fotografías y videos provocativos o con contenido de cierto nivel sexual, tomadas o grabadas por el protagonista. Para ello, los padres pueden dialogar con sus hijos sobre los posibles riesgos y consecuencias de esta práctica, brindándoles la confianza suficiente para que recurran a ellos siempre que vivan un incidente de este tipo. Otras acciones como asumir el pago de la factura de la conexión o del móvil o la supervisión del uso que hacen los menores de los dispositivos equipados con cámara (móvil, ordenador o tabletas) puede evitar situaciones de sexting.

Riesgos económicos y/o fraude: Los padres deben detectar incrementos inesperados en tarjetas de crédito, factura asociada al móvil del menor y utilizar funciones y/o aplicaciones que emitan avisos o bloquean el uso de la tarjeta bancaria o terminal cuando se supera el límite de consumo fijado. Para evitar que este colectivo sea estafado al descargar aplicaciones o contenidos, se recomienda configurar una contraseña indispensable para administrar los recursos de descarga y no dejarla en un lugar visible.

Riesgos técnicos: Fomentar desde la familia que se apliquen las mismas medidas de seguridad y hábitos de uso en el móvil o tableta que 
se utilizan con el ordenador personal: mantener actualizado el dispositivo, instalar antivirus, utilizar clave secreta o PIN, aplicación de patrones de bloqueo automático tras un periodo de inactividad del aparato, realizar copias de seguridad, etc. Hablar con los menores sobre la importancia de desactivar las características de conectividad bluetooth, infrarrojos, wi-fi, GPS y $3 \mathrm{G} / \mathrm{GPRS}$ cuando no se estén utilizando. Explicar a los hijos que las redes wi-fi públicas son menos seguras para la conexión a Internet, ya que personas malintencionadas pueden contactar con ellos o ser víctimas de piratas informáticos, con lo que su privacidad puede estar comprometida. También, se deben utilizar funciones de control parental: la mayoría de sistemas operativos móviles disponen de herramientas para que los padres restrinjan o bloqueen el acceso a contenidos, la descarga de aplicaciones, la utilización del navegador, la reproducción de videos, la geolocalización del dispositivo, el uso de la cámara, etc. Estas funcionalidades también pueden conseguirse a través de aplicaciones específicas. Si no se dispone de las funciones anteriores, se recomienda al menos instalar aplicaciones que permitan conocer el uso que se hace del Smartphone. Supervisar las aplicaciones o archivos que los menores descargan, ya que pueden contener malware. Se recomienda dar preferencia a las aplicaciones oficiales o a aquellas que provengan de fuentes de confianza. Revisar junto con los hijos las solicitudes de permisos que aparecen al realizar una descarga, valorando qué permisos se conceden (acceso a la tarjeta de memoria, conexión a Internet, intercambio de datos, etc.). Ayudar a los hijos a borrar de forma segura toda la información almacenada en el dispositivo móvil u ordenador cuando se vaya a desechar o sustituir.

\section{3. ¿Cómo actuar ante situaciones de ries-} go?: Consejos para menores

A continuación se ofrece una relación de consejos y pautas dirigidas a niños, niñas, y adolescentes, con la finalidad de ayudarles a hacer un uso más seguro de sus terminales digitales:

Uso excesivo: Tu familia es la primera referencia. Cuéntales a tus padres cómo usas el ordenador y el Smartphone y cuáles son tus preferencias. Es importante que establezcas con ellos unas reglas de uso, en especial sobre los lugares, el tiempo que puedes utilizar los dispositivos, lo que puedes hacer o ver y el límite mensual del que dispones. Así, cada usuario podrá conocer sus propios límites.

Adicción: Si te sientes agobiado, molesto o irritado, cuando no puedes conectarte (Internet o móvil) es momento de dejar el ordenador o móvil y descansar.

Acceso a contenidos inadecuados: En el momento en que determinados servicios te resulten impactantes por su violencia o su contenido sexual, coméntaselo a un adulto. Indícale cuáles son tus preferencias para que te ayude a elegir aplicaciones y contenidos que te hagan disfrutar sin sentirte incómodo.

Amenazas a la privacidad: En las redes sociales, y en general en Internet, toda la información que guardas y/o transmites puede acabar circulando por la red. Esto implica que pierdes el control sobre tu información. Reflexiona sobre 
la importancia de mantener tus datos en privado. Debes ser cuidadoso con tus datos al utilizar aplicaciones y servicios de Internet, en especial las imágenes o videos que compartas. Piensa dos veces antes de enviar una foto o video, ya que una vez que las subes a la red, pierdes el control sobre ellas. No debes hacer nada que no quieras. Si las fotos o videos son de otras personas, compañeros o amigos, piensa que estos pueden avergonzarles o comprometerles. Tanto en la vida real como en la red trata a los demás como te gustaría que te tratasen a ti. Al utilizar las redes sociales debes ser especialmente cuidadoso con la información que subes y compartes, sea tuya o de otras personas, ya que los efectos se multiplican. Configura junto a tus padres o educadores tu perfil en estas redes sociales, la política de privacidad y los términos de uso. Cierra adecuadamente la sesión al utilizar servicios web con contraseña. Así evitarás que tus datos (usuario y contraseña) permanezcan en el historial de navegación y otros puedan acceder a ellos.

Ciberbullying: Internet (ordenador o móvil) puede ser una vía de comunicación ágil y sin censura, por lo que pueden producirse situaciones de amenazas, ofensas, bulos, etc. No utilices esos dispositivos digitales para molestar o insultar a otros. Trata a los demás como te gustaría que te trataran a ti. Si eres tú el que recibes mensajes en los que se burlan o acosan a compañeros, no los reenvíes ni comentes. Si te sientes acosado, acude a un adulto. Infórmale de cualquier cosa rara o molesta que te ocurra.

Grooming: Si recibes mensajes o llamadas de desconocidos, evita responder. Tratar con desco- nocidos puede tener consecuencias desagradables. Reflexiona sobre tu forma de hacer amigos, ya que normalmente son de tu colegio, equipo deportivo, barrio, etc. ¿Necesitas conocer gente nueva?: Ve siempre acompañado por un adulto. En ocasiones, puedes recibir mensajes de carácter obsceno u ofensivo. Guárdalo y enséñaselo a tus padres o profesores, ya que ellos sabrán qué hacer.

Sexting: No fomentes ni contribuyas a que imágenes propias o ajenas de carácter provocativo circulen por Internet. Lo mejor para evitar situaciones que puedan avergonzarte es no tener imágenes o videos tuyos en actitudes provocativas o sexis. De igual forma, no reenvíes mensajes que contengan este tipo de imágenes de otras personas o amigos, aunque dejen de serlo.

Riesgos económicos y/o fraude: Si realizas compras a través de Internet (ordenador o móvil), siempre acompáñate de un adulto. En especial, presta atención a la hora de realizar descargas de apps y servicios de Internet en tu Smartphone. Comprueba el coste exacto de la descarga y pregunta a tus padres en caso de no entender este proceso. De la misma forma, si recibes mensajes que te invitan a pinchar en un enlace, comprueba previamente que es de confianza y nunca des datos bancarios o de la tarjeta de crédito o débito de tus padres, ni de ningún adulto.

Riesgos técnicos: Elige junto a tus padres la configuración de seguridad adecuada. Mantener actualizado el software del ordenador y móvil, así como las aplicaciones, disponibles en los markets o tiendas virtuales de los diferentes sistemas operativos. En general, los propios dispositivos 
te avisan de las actualizaciones disponibles para instalar en el terminal u ordenador, simplificando esta tarea. Realiza copias de seguridad periódicas, o pide ayuda para realizar este proceso. Solo tú y tus padres deben conocer el número PIN de tu teléfono o la clave y usuario de redes Wi-Fi, email, redes sociales, etc. No los lleves anotados en los propios equipos ni en tus objetos personales (carteras, mochilas, etc.). Estate atento a los virus. No descargues aplicaciones o contenidos por tu cuenta, hazlo acompañado por un adulto. En caso de que esta labor la realices tú solo, elige fuentes de confianza y aplicaciones oficiales, con las que el riesgo de sufrir una infección por malware será menor. Presta atención a los permisos solicitados. Sé precavido a la hora de conectar el móvil a tu ordenador personal o tableta. Al realizarse el escaneo de dispositivos, estos pueden estar infectados por virus. Ocurre lo mismo con las tarjetas de memoria que incorporan los teléfonos, al conectarlas a otros equipos. Es recomendable mantener desconectadas las conexiones bluetooth, Wi-Fi, 3G/GPRS cuando no las estés utilizando. Configura el bluetooth como oculto y con necesidad de contraseña. Si recibes peticiones desde otros dispositivos desconocidos para conectarte, ignóralas, ya que evitarás transferencias de contenidos no deseados. Extrema la precaución al usar redes wi-fi públicas. Con esta medida se evita que otros accedan a tu ordenador o teléfono, a la vez que aumenta la duración de la batería. Desactiva igualmente el GPS cuando no lo utilices, así otros no podrán conocer tu localización. Si pierdes el teléfono o te lo roban, acude a tus padres para que estos se pongan en contacto con el operador telefónico y lo desactiven. Cuando ya no vayas a usar el móvil o vayas a cambiar, borra toda la información del dispositivo. Y, finalmente, desconfía de mensajes o llamadas que te anuncien servicios que no hayas solicitado. 